\title{
Articulações liberais e iliberais da islamofobia na Alemanha e na França
}

\author{
Liberal and illiberal articulations of islamophobia in Germany and France
}

Bruno Mendelski'

\begin{abstract}
Resumo
Situado nas discussões acerca da integração dos muçulmanos na Europa, argumenta-se que a islamofobia está gradualmente tornando-se institucionalizada na Alemanha e na França. Isso ocorre em razão de uma articulação entre políticas liberais e iliberais. 0 primeiro tipo contrapõe os muçulmanos a valores como igualdade de gênero e secularismo; o segundo situa o Islã diante dos valores cristãoocidentais. Metodologicamente, compara-se os discursos sobre o Islã, as leis sobre a regulação religiosa no espaço público (Alemanha e França) e o estado de emergência/lei antiterrorismo (França). 0 artigo evidencia que a islamofobia é mais aprofundada na França do que na Alemanha. Ambos vivenciaram leis que indiretamente restringiram a liberdade religiosa dos seus cidadãos muçulmanos nos anos 2000, entretanto Paris executou novas medidas (leis do burkini, estado de emergência/lei antiterrorismo) nos anos 2010. Essas políticas públicas recentes reduziram ainda mais as liberdades individuais dos muçulmanos franceses. 0 declínio do item "liberdades civis" no Relatório Anual da Freedom House (2017) e a queda francesa de "full democracy" para "flawed democracy" no The Economist Democracy Index (2015) fornecem evidências para sustentar o argumento.
\end{abstract}

Palavras-Chave: Islamofobia; Islamofobia na Alemanha; Islamofobia na França; Liberalismo; Iliberalismo.

\begin{abstract}
Situated in the discussions on the integration of Muslims in Europe, the paper argues that Islamophobia is gradually becoming institutionalized in German and France. This occurs due to a link between liberal and illiberal policies. The first contrasts Muslims with values such as gender equality and secularism, while the second opposes Islam against the Christian-Western values. Methodologically it compares governmental discourses about Islam, public laws concerning state neutrality in schools (Germany), religion regulation in the public space, and the emergency state/terrorist laws (France). The article points out that Islamophobia is more in-depth in France than in Germany. Both experienced laws that indirectly restrict the religious freedom of their Muslims citizens in the 2000s, but France added to those new ones (burkini laws, emergency state/terrorist law) in the 2010s. These recent public policies further reduced individual liberties of French Muslims. The decline of "civil liberties" item of Freedom House Annual Report (2017) and France's move from "full democracy" to "flawed democracy" in The Economist Democracy Index (2015), provide evidence to support the argument.
\end{abstract}

Keywords: Islamophobia; Islamophobia in Germany; Islamophobia in France; Liberalism; Illiberalism.

\footnotetext{
1 Doutorando em Relações Internacionais pela UNB. Visiting Doctoral Student at the Department of Political Science and International Relations at University of Istanbul. Professor Assistente do Curso de Relações Internacionais da UNISC. E-mail: brunomendelskidesouza@gmail.com. Cidade: Santa Cruz do Sul.
} 


\section{Introdução}

O medo, a hostilidade e as práticas discriminatórias contra os muçulmanos e o Islã, entendidas como islamofobia, estão no centro dos debates acadêmicos contemporâneos. Essa conduta, apesar de histórica no continente europeu, começou a se tornar alvo de estudos acadêmicos somente a partir do final dos anos 1990. Entre os países que, historicamente, observaram um contencioso islamofóbico, destacam-se Alemanha e França, os quais dispõem das maiores comunidades muçulmanas da Europa. Essas minorias estão assentadas nesses países há pelo menos três gerações. A relação desses Estados com esses indivíduos tem sido conflituosa, sobretudo no que diz respeito a sua integração social e econômica.

A dificuldade em se adaptar a uma sociedade com valores centrais distintos dos de sua sociedade de origem, conjugada com uma igualmente problemática inserção no mercado de trabalho, resultou na marginalização social dessas populações, gerando, não obstante, preconceito e islamofobia para com estes indivíduos.

A esse difícil cenário somam-se importantes acontecimentos externos. A islamofobia na Europa ganhou notável impulso no pós 11 de Setembro de 2001, na esteira da Guerra ao Terror. A popularização da associação do terrorismo à religião islâmica, por alguns grupos políticos, midiáticos e da sociedade civil, contribuiu fortemente para o aumento da islamofobia na Europa.

Mais recentemente, a onda de refugiados e imigrantes de países do Norte da África e do Oriente Médio, iniciada em 2013², e o aumento expressivo do número de ataques terroristas perpetrados em solo europeu ${ }^{3}$

\footnotetext{
2 Alemanha e França se situam entre os países que mais receberam solicitações de asilo (EUROSTAT, online). O primeiro não apenas tem sido o país que, irrefutavelmente, tem recebido o maior número de imigrantes e refugiados, como vem advogando ao nível da União Europeia por maior abertura e recepção destes indivíduos pelos países membros.

3 Dentre eles, destacam-se: ataques coordenados na região de Île-de-France em 7 de janeiro de 2015, com 20 mortos e 22 feridos; ataques coordenados em Paris, em 13 de novembro de 2015, gerando 137 mortos e 413 feridos; ataque com um caminhão na cidade de Nice, em 14 de julho de 2016, ocasionando 87 mortos e 434 feridos; ataque com um caminhão na cidade de Berlim, em 19 de dezembro de 2016, resultando em 12 mortos e 56 feridos (EUROPOL, 2015; 2016; 2017).
} 
têm favorecido o aumento de hostilidades em relação ao Islã e aos muçulmanos.

A islamofobia se expressa tanto pelo poder público quanto na sociedade civil. No primeiro caso, ela se manifesta de duas formas: retoricamente, via declarações, discursos e pronunciamentos de representantes públicos, e por meio de politicas públicas, via legislações que restrinjam ou retirem direitos dos muçulmanos. No segundo caso, a islamofobia se manifesta na sociedade civil através de ataques verbais e físicos a muçulmanos ou contra mesquitas, centros islâmicos ou propriedades de muçulmanos.

O presente trabalho investiga a manifestação governamental da islamofobia na Alemanha e na França, no período que sucede o 11 de Setembro até a atualidade ${ }^{4}$. O objeto de estudo serão as declarações de líderes políticos alemães e franceses, bem como as leis alemãs (2004, 2005, 2006) e francesas $(2004,2010)$ que abordam o uso de simbolos religiosos em escolas e nos espaços públicos; o decreto presidencial francês que instituiu o estado de emergência no país (2015 - transformado em lei antiterrorismo em 2017), e as leis municipais francesas sobre o burkini (2016).

Essas legislações representam as principais políticas públicas executadas por Berlim e Paris que impactam suas comunidades muçulmanas. Já o problema de pesquisa do trabalho pode ser sintetizado na seguinte pergunta: como se dá a articulação de pressupostos e práticas liberais e iliberais nas principais politicas públicas alemãs e francesas em relação à integração de suas comunidades muçulmanas?

Sustenta-se que a islamofobia está gradualmente tornando-se institucionalizada na Alemanha e na França, adquirindo traços mais profundos em Paris. As recentes políticas públicas francesas (leis do burkini, estado de emergência/lei antiterrorismo) e os últimos relatórios da Freedom House e da The Economist Index, fornecem evidência para esse argumento.

Argumenta-se, igualmente, que a institucionalização da islamofobia depende de uma articulação entre discursos e práticas liberais e iliberais. O

\footnotetext{
4 A islamofobia na sociedade civil não será investigada nesse trabalho em razão do reduzido espaço inerente a um artigo científico. 
primeiro movimento, discursivo, visa marginalizar os muçulmanos e o Islã através de sua contraposição a valores liberais, como a igualdade de gênero e o secularismo. Argumentos não liberais como a incompatibilidade do Islã aos valores morais, culturais e religiosos cristão-ocidentais, também são empregados discursivamente para a defesa de práticas discriminatórias aos muçulmanos.

O segundo movimento é institucional e corresponde à materialização dessas retóricas em leis e politicas públicas, utilizadas como evidências do processo em exame. Essas políticas públicas assumem características iliberais ao gerarem restrições às liberdades fundamentais de parte dos indivíduos.

Destarte, por meio dos conceitos de islamofobia liberal e islamofobia iliberal percebe-se o grande paradoxo verificado pela ação estatal na Alemanha e na França: a defesa de valores liberais como o secularismo e a igualdade de gênero gerou práticas iliberais que atacaram direitos fundamentais dos indivíduos em razão de suas preferências religiosas.

Com o auxílio da concepção de liberalismo perfeccionista, constata-se o empenho dos estados alemão e francês em disciplinar os seus cidadãos de acordo com o que os mesmos entendem como valores nacionais. Tal prática revelou-se excludente e discriminatória, visto que, em nome da preservação dos valores politicos (liberalismo) e culturais (Cristianismo na Alemanha e laicidade na França), se permitiu a violação de direitos fundamentais como a liberdade de expressão e a liberdade religiosa.

De modo a lançar luz sobre essas questões, o artigo está dividido em quatro seções, além desta. A próxima apresenta e discute os principais conceitos que serão utilizados no trabalho. Posteriormente, examinam-se em separado, as políticas públicas na Alemanha e na França e sua relação com a islamofobia. Por fim, conclui-se que as políticas públicas analisadas da Alemanha e França, apesar de serem sustentadas em pressupostos distintos, neutralidade estatal no primeiro e laicidade no segundo, compartilham articulações entre mecanismos liberais e iliberais que resultam em práticas islamofóbicas. 


\section{Liberalismo, iliberalismo e islamofobia: uma breve discussão}

O liberalismo como corrente filosófica e política, apesar de suas diversas abordagens, possui como tronco comum a defesa do indivíduo contra o poder estatal ou societal (MATTEUCCI, 1998). Esse entendimento fora desenvolvido por filósofos como Locke [1689] (2001) e Mill [1847] (1991). O primeiro (2001) argumentava que era dever do Estado preservar os direitos dos cidadãos à vida, à liberdade, e à propriedade. O segundo (1991), advogando em prol da autonomia individual, pontuava que a única finalidade que justifica a interferência dos homens na liberdade de ação de seus pares, é a autoproteção.

O liberalismo clássico caracteriza-se como um corpo de formulações teóricas que defende um Estado constitucional e uma ampla margem de liberdade civil. Em termos doutrinais, há três elementos: a teoria dos direitos humanos, o constitucionalismo e a economia clássica liberal (MERQUIOR, 2014). Historicamente, o Estado liberal surge de uma contínua erosão do poder monárquico absolutista europeu, fomentada por demandas societais por maior liberdade.

Mais contemporaneamente, Bobbio (2000) reafirma o ideal liberal de defesa de direitos fundamentais aos indivíduos, pontuando que o pressuposto filosófico do Estado liberal consiste no entendimento de que todos os homens têm, por natureza, direitos fundamentais, como o direito à vida, à liberdade, à segurança e à felicidade, direitos que esse Estado deve assegurar e respeitar. Similarmente, Matteucci (1998) assinala que o liberalismo defende as liberdades de religião, expressão, associação e participação no poder político, assim como a não interferência estatal nessas esferas.

Também é importante destacar que liberalismo e democracia possuem construções históricas próprias e nem sempre se encontram conectados (BOBBIO, 2000). Exemplos históricos demonstram que um Estado liberal não é, necessariamente, democrático (Chile de Pinochet, 1973- 
90); e um governo democrático não dá vida, necessariamente, a um Estado liberal (Hungria de Orban, 2010-).

Uma dificuldade enfrentada por Estados liberais, em seu esforço de garantir a primazia dos direitos fundamentais individuais, diz respeito aos direitos dos indivíduos e grupos que não partilham desse ideal liberal.

Kymlicka (1995) chama a atenção para este ponto: o fato de uma minoria praticar e defender práticas não liberais não legitima a imposição, pelo Estado, de princípios liberais a ela. O autor (1995) aprofunda a discussão, colocando que esta posição não é imperativa. A seu juízo, os liberais não têm o direito nem a responsabilidade de posicionar-se contra determinadas práticas iliberais injustas, podendo, no entanto, apoiar movimentos reformistas liberais dentro destas minorias. A prática dos principios liberais resulta, assim, de um processo de convencimento e adoção voluntária, pelos indivíduos, de regras de jogo pautadas por esses princípios.

Segundo Riley (2007), a autonomia individual se encontra no centro das premissas liberais, porém o pluralismo permanece como um princípio proeminente. Isso significa que o liberalismo tem que navegar por dificeis águas, de modo a manter os direitos individuais e acomodar uma variedade diversificada de culturas e organizações. Nesse processo de garantia de direitos individuais e convivência com a diferença, uma eventual ação estatal que fira a liberdade individual, de modo a impor principios vistos como corretos, pode traduzir-se como um ato iliberal.

Um interessante exemplo do relacionamento entre liberalismo e iliberalismo pode ser observado no paradoxo da democracia. Esse conceito evidencia a complexa relação entre a garantia das liberdades fundamentais e o direito dos indivíduos expressarem ideias antidemocráticas ou iliberais. Desse modo, a possibilidade de grupos defenderem a extinção do regime democrático e liberal pode ocorrer em nome de suas liberdades individuais. Tal situação é ainda mais problemática se grupos que preguem essa agenda vencessem eleições e passassem a implementar essas medidas iliberais. Esse 
exemplo representaria o extremo da posição liberal acerca das liberdades fundamentais.

Dentro do estudo dos limites de ação do Estado liberal, o conceito de iliberalismo, não possui uma definição comumente aceita (RILEY, 2007). Contudo, sua essência reside na defesa de principios antagônicos ao liberalismo. De acordo com Rosanvallon (2001), iliberal é aquela cultura politica que desqualifica em seu princípio, a visão liberal. Os elementos definidores da perspectiva liberal podem ser resumidos nas liberdades individuais lockeanas: direitos à vida, à liberdade (religião, expressão e associação) e à propriedade. Todavia existe uma literatura que trata especificamente do conceito de iliberalismo, e que merece ser revisitada.

Para Kymlicka (1995), grupos iliberais são aqueles que simplesmente atribuem determinados papéis e deveres ao povo, impedindo-os de questionar esses processos. Em seu estudo sobre o iliberalismo, Stephen Holmes (1993), aponta que a restrição aos principios liberais fundamentais, resulta em uma sociedade iliberal. Tais princípios são: 1) segurança pessoal; 2) imparcialidade do Estado em suas decisões perante os indivíduos; 3) liberdade individual; 4) direito de participar no processo de produção das leis por meio de eleições e discussões públicas via liberdade de imprensa.

Ekeli (2012), por sua vez, pondera que o iliberalismo apresenta-se na rejeição de ao menos um dos seguintes pressupostos liberais: liberdade e igualdade entre os cidadãos; respeito à autonomia individual; tolerância; entendimento de que todos os indivíduos dispõem de um status moral igual e de que o Estado tem o dever de respeitar e proteger os direitos fundamentais políticos e civis; apreço pelas instituições democráticas, como eleições livres, abertas e periódicas.

Brint (2001) aponta como características do iliberalismo, além da restrição da autonomia individual: 1) emprego regular de pesadas formas de controle social para reforçar a concordância; 2) criação de desvios como meios para encorajar a coesão comunitária; 3) estabelecimento de fronteiras fortemente diferenciadas entre membros e não membros, encorajando preconceitos contra não membros. 
Dentro das definições trazidas de iliberalismo destacam-se dois pontos comuns: o cerceamento aos direitos fundamentais (em específico a limitação da liberdade individual) e a disposição em adotar posições intolerantes com relação às minorias. Serão justamente esses itens que aparecerão como foco de discussão e tensão, gerados pelas leis alemãs e francesas que regulamentam o uso de símbolos religiosos. Mesmo assumindo que o uso do véu islâmico ${ }^{5}$ constitui uma prática iliberal, pode-se questionar a imposição de valores liberais como meio de combater ações iliberais, sobretudo se essa imposição viola direitos fundamentais, como a liberdade individual.

O ponto em questão não se refere à discussão sobre a radicalidade dos direitos fundamentais, mas sim, sobre as justificativas para a sua restrição, argumentos estes que podem dispor de traços iliberais. Pois, para o liberalismo, o Estado tem a prerrogativa de limitar a liberdade individual, desde que o faça através do Direito, sendo este uma expressão de um querer comum (MATTEUCCI, 1998). Nesse sentido, a interrogação a ser feita é: de qual "querer comum" estamos falando? Trata-se da vontade e valores da maioria?

Se assumirmos que a laicidade é um valor da maioria da população francesa e que o Estado contemporâneo francês se constrói sobre essa base filosófica-ideacional, as leis do país que regulam o uso de símbolos religiosos em espaços públicos não teriam um caráter iliberal para aqueles indivíduos que utilizam tais adornos? Para Kymlicka (1995) a imposição de normas liberais pode ter um caráter consideravelmente prejudicial para aqueles a quem elas se destinam. O autor prossegue (1995) evidenciando que as relações entre maioria e minoria em um Estado multinacional deve ser determinada pela negociação pacífica e não pela força, procurando bases comuns de entendimento.

\footnotetext{
5 Tradicionalmente, existem três tipos de véu islâmico: o hijab, o niqab e a burca. O primeiro é o mais utilizado por mulheres muçulmanas na Europa e consiste em um véu que cobre o pescoço e o cabelo. O segundo constitui-se de um véu para o rosto que deixa somente a área ao redor dos olhos a mostra. Por fim, a burca abrange todo o corpo, deixando apenas uma tela de malha para a visão feminina, sendo este adorno o tipo de véu islâmico menos usado por mulheres muçulmanas na Europa. Quando mencionados os termos "véu" ou "véu islâmico" neste trabalho, faz-se referência ao hijab (BBC, online).
} 
A imposição de preceitos liberais também pode ser analisada pelo viés daquilo que O’Brien (2016) definiu como liberalismo perfeccionista. O termo é utilizado para designar o comportamento de alguns Estados da Europa Ocidental que buscam enfatizar a liberdade por meio de uma ação incisiva do Estado, com o intuito de moldar os cidadãos como praticantes e defensores da liberdade. Procura-se formar não uma sociedade liberal, mas uma sociedade de liberais, onde a liberdade vem por meio do Estado (ibidem). A dificuldade no relacionamento com minorias muçulmanas, fomentada por um conjunto de preconceitos, é um dos pontos trazidos ao debate por meio do conceito de islamofobia.

Segundo Allen (2007), o termo islamofobia começou a ganhar destaque e projeção a partir de sua discussão no relatório Islamophobia: a Challenge for Us All da Runnymede Trust (1997). O documento define islamofobia como: "infundada hostilidade em relação ao Islã". O trabalho ainda afirma que a islamofobia se refere, também, aos aspectos práticos de tal hostilidade, "a qual consiste em uma infundada discriminação em relação aos indivíduos e comunidades muçulmanas, e à exclusão dos muçulmanos do mainstream político e dos assuntos sociais" (RUNNYMEDE TRUST, 1997, p. 1, tradução livre). A despeito dessa definição inicial, proposta pelo Runnymede Trust, não existe consenso acerca de um sentido comum a ser atribuído ao termo (ALLEN, 2007; BLEICH, 2012; CESARI, 2011; MONDON e WINTER, 2017).

$\mathrm{Na}$ Alemanha, além da islamofobia, dois outros termos (muito próximos entre si) são empregados: islamfeidlichkeit e muslimfeindlichkeit. Esses remetem a um sentimento de hostilidade anti-Islã e anti-muçulmanos, o qual não implica, necessariamente, medo (CESARI, 2011; ARANI, 2015). Na Françaé comum o uso da expressão racisme anti-arabe (ou racisme antimaghrébin 9 , que indica que o fenômeno é visto, principalmente, como uma forma de racismo anti-imigração árabe-magrebina (KAYA, 2016).

\footnotetext{
6 O próprio uso desses termos contribui para empobrecer o estudo do fenômeno, visto que nem todos os magrebinos são árabes ou muçulmanos, e nem todos os árabes são muçulmanos ou magrebinos. Ademais, o contexto francês, no qual a maioria dos muçulmanos franceses possuem origem árabe e magrebina, igualmente auxilia para esse entendimento errôneo.
} 
Também cabe mencionar que o termo islamofobia encontra resistências na academia, sobretudo na francesa. Para Kepel e Rougier (2016), o uso do vocábulo islamofobia torna difícil a visualização dos usos ideológicos do Islã por grupos e indivíduos (KEPEL e ROUGIER, 2016). Kepel (2017) afirma que a difusão do conceito de islamofobia tem impedido e desestimulado uma visão crítica ao Islã, transformando os muçulmanos em vítimas.

A enfática defesa do caráter laico da sociedade francesa e a problemática integração dos muçulmanos (vistos sob a ótica de um Islã segregacionista e expansionista) são os principais argumentos dos intelectuais críticos ao uso do termo islamofobia. Finkelkraut (2013) questiona a atribuição do vocábulo para as leis que visam a integrar os muçulmanos aos valores nacionais franceses, pontuando que determinados grupos, amparados na retórica contra o racismo anti-muçulmano, buscam subordinar a França ao Islã. Para o autor (2013, online), a verdadeira islamofobia seria dizer: "sua religião é incompativel com nossa identidade, você não tem nada para fazer aqui."

Exposta essa crítica ao vocábulo islamofobia, avançamos em dois pontos que se interligam: a manifestação da islamofobia como política pública e sua exposição por meio de práticas liberais e iliberais, tendo como referência a Alemanha e a França. Contudo, é importante mencionar que o presente artigo empregará em sua análise a conceituação proposta por Bleich, por acreditar que ela capta com eficácia os dois elementos centrais da islamofobia - os eixos discursivo e prático: "atitudes negativas indiscriminadas ou emoções dirigidas ao Islã ou a muçulmanos” (2012, p. 1582, tradução livre).

Também é relevante evidenciar a compreensão do termo políticas públicas que o trabalho utilizará. Entende-se por politicas públicas o conjunto das decisões e ações do poder público relativas à alocação imperativa de valores (RUA, 1997). Elas envolvem decisões politicas demandando diversas ações, estrategicamente, selecionadas para implementar as decisões tomadas (ibidem). As políticas públicas são 
caracterizadas como uma ação intencional de longo prazo dos governos a determinadas demandas da sociedade (SOUZA, 2006). Um exemplo desta ação governamental, que será objeto deste trabalho, são as leis alemãs (2004, 2005, 2006) e francesas $(2004,2010$ e 2016), que versam sobre o uso de símbolos religiosos em escolas e no espaço público, bem como o decreto presidencial francês que instituiu o estado de emergência no país (2015), transformado posteriormente em lei antiterrorismo (2017).

Atitudes islamofóbicas executadas pelo poder público são melhor analisadas por meio dos conceitos de islamofobia liberal e islamofobia iliberal (MONDON e WINTER, 2017). Os autores sugerem entender a islamofobia como uma articulação de discursos e práticas liberais e mainstream com posturas iliberais e racistas. A islamofobia liberal se encontra no mainstream por criticar abertamente o racismo, mas se articula na "religião", "cultura" e "valores" em sua oposição ao Islã. Ela é ancorada em uma narrativa pseudoprogressista de defesa do estado de direito baseado na igualdade liberal, liberdades e direitos. A França é apontada pelos autores (2017) como um exemplo onde, apesar de a islamofobia liberal ser hegemônica, ela é influenciada por ideais da islamofobia iliberal.

Ainda utilizando Paris como referência, Mondon e Winter (2017) apontam que a islamofobia liberal se operacionaliza por meio da retórica e prática dos princípios de direitos de gênero e secularismo. O primeiro valor é utilizado como mecanismo legitimador de discursos e práticas islamofóbicas, tendo como base o entendimento que o Islã é uma religião opressora para as mulheres. E o secularismo tem sido empregado como escudo para tentar proibir a publicização do Islã, como pode ser observado nas leis francesas de 2004 e 2010 que, respectivamente, proíbem o uso de símbolos religiosos extravagantes em escolas e o uso de véus que cubram a face em espaços públicos (ULGER e BENITEZ, 2017).

Já a islamofobia iliberal tende a emergir de ideologias exclusivistas, discursos e identidades associadas a formas facilmente reconheciveis de racismo, tipicamente originárias da extrema-direita e dos círculos ultraconservadores. Ela frequentemente apresenta o Islã como um bloco monolitico e inatamente ameaçador e inferior, em termos raciais e/ou 
culturais (MONDON e WINTER, 2017). Para os autores a articulação da islamofobia iliberal possui dois elementos centrais: 1) afastamento do liberalismo por defender práticas discriminatórias baseadas na cultura, etnicidade e/ou religião, mas ao mesmo tempo compartilhando posições tradicionais do racismo; 2) seu caráter essencialista, violento e discriminatório.

Dessa forma, a islamofobia iliberal ancora-se na tradição iliberal de tratamento desigual destinado a certos grupos (baseado em generalizações étnicas ou culturais), resultando, muitas vezes, no contorno do estado democrático de direito (ibidem). A ideia central dos autores (2017) consiste na afirmativa de que a islamofobia só consegue ser naturalizada e incorporada pelo senso comum porque é exposta tanto pela vertente liberal da islamofobia, quanto pela sua vertente iliberal. Essa complexa articulação será evidenciada nas seções seguintes, que tratam das principais politicas públicas alemãs e francesas aos muçulmanos.

\section{As políticas públicas e a islamofobia na Alemanha}

Apesar de não existirem estatísticas oficiais do governo alemão sobre a demografia religiosa, a Pew Research Center (2017) estima que 5,8\% dos alemães sejam muçulmanos. São cerca de 4,950 milhões de indivíduos, a segunda maior comunidade muçulmana da Europa (PEW RESEARCH CENTER, 2017). Destes, aproximadamente a metade é de origem turca (GERMAN 2016 INTERNATIONAL RELIGIOUS FREEDOM REPORT, 2016).

Historicamente, na Alemanha o preconceito e o racismo eram direcionados aos estrangeiros de modo geral (LORASDAGI e INCE, 2011). Porém, na contemporaneidade, especialmente após o 11 de Setembro, parte considerável da sociedade alemã substituiu a "etnização" de determinadas questões sociais por uma "islamização", trocando o preconceito tradicional aos "estrangeiros" e "turcos" para os muçulmanos (ARANI, 2015).

Eventos como esse, somados ao súbito aumento no ingresso de indivíduos muçulmanos advindos da recente onda de refugiados que atinge a 
Europa, e a elevação do número de atentados terroristas no continente, impulsionaram o crescimento da hostilidade contra os estrangeiros e aos muçulmanos em específico, influenciando as políticas de integração da Alemanha. Somente em 2017 houveram no país 76 manifestações contra a “islamização do Ocidente" e cerca de 1.900 ataques contra refugiados. Esses números indicam que a islamofobia é força fundamental no racismo alemão contemporâneo e uma força motriz contínua na sociedade alemã (YOUNES, 2018).

$\mathrm{Na}$ Alemanha, assim como na França, a regulamentação legal do uso do véu islâmico em público constitui-se na maior controvérsia envolvendo a ação estatal diante as suas respectivas comunidades muçulmanas. No cerne da questão encontra-se a compreensão de que o hijab é visto como uma ameaça ao secularismo, cultura cristã, progresso feminista, iluminismo alemão, e valores europeus (WEBER, 2012). O debate público sobre a possibilidade de professoras de escolas públicas usarem o véu nos seus empregos iniciou-se no final dos anos 1990, no parlamento do estado de Baden-Württemberg (HUMAN RIGHT WATCH, 2009). A Ministra da Cultura de Baden-Württemberg, Annette Schavan (partido CDU7), em 1997 argumentou que vestir o véu não se tratava de moda, mas sim de um sinal de exclusão, um sinal de diferença vis-à-vis outras fés. Para ela o adorno pode, inclusive, representar uma resistência aos objetivos de integração ou assimilação (WEBER, 2004).

A discussão fortaleceu-se quando uma professora alemã de origem afegã, após ter sido impedida de trabalhar em uma escola pública em Stuttgart por usar o véu, entrou com recurso à Suprema Corte Constitucional Alemã contra a escola em questão (LETTINGA e SAHARSO, 2014). Em uma decisão dúbia sobre o tema, o órgão em 2003 afirmou que a proibição do uso do hijab pela professora era injustificada, em razão do estado de Baden-Württemberg não possuir nenhuma lei que proibisse tal prática. O ente público, igualmente, colocou que caberia aos estados da

\footnotetext{
7 A União Democrática Cristã (CDU) é o principal partido conservador da Alemanha. Governa o país desde a $1^{\text {a }}$ eleição da chanceler Angela Merkel em 2005.
} 
federação alemã incluir leis sobre esse assunto em suas constituições (JONES e BRAUN, 2017).

A partir dessa deliberação a matéria projetou-se nacionalmente ganhando, inclusive, o apoio do então chanceler Gerhard Schroeder, que afirmou em 2003 que não havia espaço para o véu no serviço público (HUMAN RIGHT WATCH, 2009). Nesse processo, e em pouco tempo, metade dos estados alemães incluíram em suas constituições leis que proibiram o uso do véu por professoras em escolas públicas, sob o argumento de que a vestimenta simbolizava a não integração e infringia a neutralidade estatal, bem como negava a liberdade religiosa dos estudantes e de seus pais (JOPPKE, 2007c).

Deste modo, a legislação promulgada nos estados de BadenWürttemberg (2004), Baixa Saxônia (2004), Bavaria (2004), Saarland (2004), Hesse (2004), Berlin (2005), Bremen (2005) e Rhine-Westphalia do Norte (2006), proibiu o uso de símbolos religiosos por professores em escolas públicas alemãs ${ }^{8}$. É interessante observar que nenhuma dessas leis que banem os símbolos religiosos explicitamente mencionam o véu islâmico; porém, como pode ser observado em sua vigência prática, a norma atingiu, majoritariamente, as professoras que usavam esse adorno (HUMAN RIGHT WATCH, 2009).

Apesar de as leis alemãs compartilharem com suas homólogas francesas conteúdos discriminatórios, apresentam uma significativa diferenciação conceitual. Segundo Joppke (2007b), os princípios basilares que normatizam a separação entre Estado e religião na Alemanha e França são distintos, com Paris possuindo fundamentos mais rigorosos que Berlim. Na Alemanha, o secularismo é operacionalizado por meio do conceito de neutralidade estatal, que obriga o Estado a garantir que todos os indivíduos possam exercer suas religiões na esfera pública e privada, tratando todas as religiões igualitariamente e imparcialmente. Já na França, o pressuposto de

\footnotetext{
8 Nos estados de Berlim e Hesse, o banimento do uso de símbolos religiosos se estende a policiais, juízes e demais funcionários do judiciário (LETTINGA e SAHARSO, 2014).
} 
laïcité caracteriza-se pela rígida separação entre Estado e religião, estando a religião destinada somente à esfera privada (JOPPKE, 2017).

Com relação as leis alemãs, é salutar destacar que existe uma articulação entre pressupostos liberais e iliberais, que resultam no caráter islamofóbico das legislações. A defesa da secularização dos espaços públicos é, tradicionalmente, uma agenda liberal. Porém, conforme sustentam Mondon e Winter (2017), o argumento da necessidade de secularização dos espaços públicos tem sido chave para a ação da islamofobia liberal. Nesse sentido, uma justificativa liberal acaba por gerar uma prática iliberal: restrição de liberdades individuais (impossibilidade do uso de adornos religiosos). Analisando o caso pela ótica do liberalismo perfeccionista, observa-se que, para esse conceito, não existe local mais apropriado para o Estado liberal forçar seus cidadãos a serem livres do que a escola (O’BRIEN, 2016).

Orgad acrescenta, ainda, que as politicas que os Estados europeus vêm executando no âmbito da integração de suas minorias têm gerado um paradoxo do liberalismo, onde "Estados liberais, de modo a preservar o que eles entendem como regime liberal estão recorrendo a meios iliberais de modo a garantir valores liberais" (2010, p. 92, tradução livre). O comportamento expresso nessas leis parece encaixar-se no conceito de liberalismo perfeccionista (O’Brien, 2016), em que o Estado liberal europeu procura, incisivamente, moldar os cidadãos como praticantes e defensores da liberdade.

Prosseguindo com a análise, o fato de quase todos os Estados, em suas leis, permitirem exceções para símbolos cristãos-ocidentais evidencia que o iliberalismo não se apresenta somente como fim, mas que ele se encontra igualmente como fundamento para a lei. Segundo Mondon e Winter (2017), o tratamento diferenciado a certos grupos, tendo como base a cultura, religião ou etnicidade, consiste em um elemento central da islamofobia iliberal.

Nesse sentido, o caráter islamofóbico das legislações alemãs possui algumas interessantes especificidades. Com exceção de Berlim, todos os demais estados alemães que criaram leis para restringir o uso do véu por 
professoras em escolas públicas, permitem exceções para símbolos "cristãosocidentais", por considerarem os mesmos como integrantes da cultura e valores alemães (O’BRIEN, 2016).

Corinna Werwigk-Hertneck (partido FDP ${ }^{9}$ ), Ministra da Justiça do Estado de Baden-Württemberg na época da promulgação da lei, afirmou, em 2004, que os véus são diferentes das cruzes porque as crianças precisam aprender sobre as raízes do cristianismo e da cultura europeia (LORASDAGI e INCE, 2010). Monika Hohlmeier (CDU), então Ministra da Cultura da Bavária, ao justificar em 2004 a possibilidade da exibição de símbolos religiosos cristãos, adota tom mais incisivo e islamofóbico, advogando por uma proibição legal para os "potenciais inimigos da constituição", acrescentando que "nós não devemos abrir a porta para o fundamentalismo e extremismo". Ela pontuou, ainda, que a matéria era diferente de freiras usando o seu hábito enquanto lecionavam e da exposição de crucifixos, porque as igrejas já haviam declarado sua aliança perante os valores sociais básicos (ibidem).

Um ponto importante a ser destacado consiste na observação de que o posicionamento contrário ao véu não ocorre, somente, pelo principal partido alemão, o CDU de Angela Merkel, mas também por uma parte significativa da segunda maior força partidária, o $\mathrm{SPD}^{10}$. A fala de Peter Wintruff (SPD) em 2004, quando este era deputado em Baden-Württemberg, é bastante explicativa nesse sentido:

Diferentemente do véu, o crucifixo pertence à nossa cultura Ocidental, à nossa tradição e possui um alto nível como evidência religiosa de amor fraternal, tolerância e dignidade humana. (...) Nós entendemos que o mandato constitucional indica educar nossas crianças de acordo com os valores culturais ocidentais e cristãos. A neutralidade estatal em nossas escolas pode, ao contrário do Estado laico, reconhecer a expressão religiosa, mas somente àquela que não viole os direitos humanos incorporados (LETTINGA e SAHARSO, 2014).

\footnotetext{
9 Partido Democrático Liberal (FDP), orientação ideológica liberal (SPIEGEL, Online).

10 Partido Social Democrata da Alemanha (SPD), de orientação ideológica de centro-esquerda, é um dos dois grandes partidos alemães, junto com o CDU (SPIEGEL, online).
} 
Essas falas deixam perceptível a íntima relação entre pressupostos liberais e iliberais, os quais atuam de maneira discriminatória com relação àqueles que não compartilham os valores europeus da matriz secularcristão. Nesta linha, Orgad (2015) coloca que obrigar os cidadãos a se familiarizarem com determinada cultura (mesmo que apenas cognitivamente), pode qualificar determinada política pública como iliberal, uma vez que tais questões não se relacionam com o funcionamento da democracia liberal e estão fora do âmbito do liberalismo político. Com a chegada do partido de extrema-direita "Alternativa para a Alemanha" (AfD) à condição de terceira maior força no parlamento, a partir da eleição de setembro de $2017^{11}$ a tendência é que políticas de caráter islamofóbico ganhem ainda mais força e apoio político (THE GUARDIAN, 24.09.17)

A Human Rights Watch (2009), em estudo específico sobre as referidas leis alemães, sustenta que estados que banem vestimentas religiosas, mas que permitem exceções para símbolos cristãos explicitamente empreendem discriminações por meio da fé. A organização afirma que as leis efetivamente forçam as mulheres a escolher entre o seu emprego e a manifestação de sua fé, violando assim o direito à liberdade religiosa e ao tratamento igualitário perante a lei. Avançando sobre o assunto, Weber (2012) afirma que as leis aprovadas por estes estados alemães (com exceção de Berlim) sugerem que o Cristianismo tem sido privilegiado como uma tradição pertencente ao estado secular alemão. Neste sentido, a islamofobia funciona especificamente através de práticas institucionalizadas do secularismo (SEZGIN, 2009 apud WEBER, 2012).

Joppke (2014) ao refletir sobre a problemática da integração do Islã nas sociedades da Europa Ocidental afirma que os esforços de normatização do corpo feminino têm empurrado o Estado liberal rumo a uma regulação legal da moral, colocando dessa forma em risco o próprio liberalismo. Ao buscar regular a moral, ao preço de restringir as liberdades individuais, o Estado liberal coloca em risco a sua liberalidade. Esse parece ser justamente

11 A nova divisão dos assentos no parlamento alemão ficou da seguinte maneira: CDU/CSU - 34,7\%, SPD - 21,6\%, AfD - 13,3\%, FDP - 11,3\%, Die Linke (extrema-esquerda) - 9,7\% e Verdes - 9,4\% (THE GUARDIAN, 24.09.17). 
o caso das leis alemãs, onde argumentos liberais podem ser reunidos para justificar restrições em instituições públicas, sobretudo na escola (ibidem).

Ademais, as medidas estudadas indicam que o Estado alemão procura disciplinar o comportamento de seus cidadãos em torno do liberalismo, em consonância com a ideia de liberalismo perfeccionista. Os comentários de O’Brien sobre o conceito parecem se encaixar no contexto alemão: "existe um nítido elemento no liberalismo perfeccionista que se esforça para moldar os muçulmanos em liberais confiáveis" (2016, p. 100, tradução livre).

Assim, práticas iliberais como o cerceamento da liberdade e a violação da autonomia individual associam-se a leis que procuram se legitimar por meio de argumentos liberais como a igualdade de gênero ou o racionalismo. Tal-qualmente o caráter prático de iliberalidade das leis, parte dos argumentos das mesmas reside em uma retórica abertamente iliberal que evoca direta e indiretamente a tese do "Choque de Civilizações" com seu pressuposto de barreiras e desconfianças entre as religiões. Esse raciocínio se insere no conceito de islamofobia iliberal (MONDON e WINTER, 2017).

Exposto e discutido o tema da islamofobia nas politicas públicas alemãs, pode-se agora partir para o caso francês.

\section{As políticas públicas e a islamofobia na França}

A França, assim como a Alemanha, não dispõe de estatísticas oficiais sobre a sua realidade demográfica religiosa. De acordo com a última estimativa da Pew Research Center (2017), 8,8\% da população francesa pertence ao credo muçulmano. Isso representa cerca de 5 milhões e 700 mil muçulmanos franceses, o que torna a França o país com a maior comunidade muçulmana da Europa (PEW RESEARCH CENTER, 2017).

Porém, ao contrário da Alemanha, onde a questão da islamofobia constitui um problema mais recente, na França ele possui raizes mais 
profundas. Ancorada num passado colonial ${ }^{12}$ profundamente enraizado, as elites francesas têm manufaturado a questão muçulmana por décadas, confinando a comunidade muçulmana francesa à posição de estrangeiros dentro de uma nação (LOUATI, 2017).

$\mathrm{Na}$ esteira do período da descolonização, a França recebeu milhares de indivíduos de suas ex-colônias. Em contraste com a Alemanha, onde a maior parte dos cidadãos muçulmanos é de origem turca, na França eles advêm sobretudo da região do magrebe árabe. Segundo Louati (2017) os franceses muçulmanos são tratados, tradicionalmente, como diferentes e estrangeiros no país, mesmo quando se refere a cidadãos franceses da terceira e da quarta geração.

A hostilidade aos muçulmanos na França se intensificou com a pressão exercida por eventos como o 11 de Setembro, a Guerra ao Terror, a atual onda de imigração e o crescente número de atentados terroristas ocorridos no país nos últimos anos. Desde 2015, a França se constituiu no Estado europeu que mais sofreu ataques terroristas, sendo também aquele que apresentou o maior número de mortes por essas ações (EUROPOL, 2016). Igualmente, nos últimos três anos, a França tem sido o país europeu que mais realizou prisões de suspeitos de praticar atos terroristas (EUROPOL, 2015; 2016; 2017).

A França pode ser considerada um interessante caso em que a articulação da islamofobia liberal se tornou mainstream e foi normalizada na sociedade (MONDON e WINTER, 2017). A ideia de secularismo (laicité) é tanto um princípio quanto uma norma constitucional na França desde 1905, quando foi proclamada a separação entre Estado e Igreja (ULGER e BENITEZ, 2017). Esse princípio tem sido usado por parte dos politicos governistas franceses para marginalizar os muçulmanos (GEISSER, 2010).

Durante a década de 1980, no contexto de um fluxo de imigrantes muçulmanos chegando à França, a discussão e promulgação de leis regulando a religião em espaços públicos tornou-se um assunto em ascensão. Para Asad (2006) o uso do véu por garotas muçulmanas constitui-

12 Entre os territórios com população majoritariamente muçulmana que foram colonizados por Paris estão: Argélia, Mali, Mauritânia, Marrocos, Níger, Senegal, Tunísia. 
se do simbolo da falta de integração social por parte de imigrantes islâmicos e sua recusa aos valores seculares franceses. Analisando a controvérsia do hijab na sociedade francesa, Gasser pontua que:

o hijab é largamente identificado pela maioria dos franceses como a expressão de um "Islã ameaçador" e como o símbolo de um novo fundamentalismo islâmico, o qual põe em perigo os valores fundamentais de secularismo e republicanismo. Por essa razão, o hijab islâmico não é considerado um mero sinal de modéstia feminina, ou uma simples vestimenta religiosa, mas sim um perigo social causador de um problema de segurança (2010, p. 43-44, tradução livre).

O autor afirma que o processo emotivo gerado pelo uso do hijab encorajou a lei de 11 de fevereiro de 2004, que proibiu a vestimenta de símbolos religiosos nas escolas públicas. Em específico, o artigo $1^{\circ}$ da lei afirma que: "nas escolas públicas primárias e secundárias, o uso de símbolos ou vestimentas por estudantes que visivelmente manifestem uma afiliação religiosa é proibido" (LOI, 2004-228, tradução livre). Ao contrário da maioria das leis alemãs que abrem exceções para símbolos cristãos, a homóloga francesa vale para todas as religiões.

Apesar de versar sobre todos os credos, a legislação atingiu diretamente as estudantes muçulmanas que usavam o hijab. Somente no primeiro ano letivo após a implementação da lei, ocorreram 639 casos relacionados ao uso de símbolos religiosos em escolas. Desses, 97,96\% (626 casos) envolveram o uso do véu, 1,72\% (11 casos) o turbante sikh e 0,31 (2 casos) a utilização de crucifixos (RAPPORTEUR HANIFA CHÉRIFI, 2005). Nessa linha, Geisser (2010, p. 44, tradução livre) afirma que "na verdade, trata-se de uma lei islamofóbica direcionada contra o hijab".

A esta constatação prática acerca da lei de 2004, soma-se a retórica dos líderes politicos sobre o assunto. No âmbito discursivo é possivel perceber não apenas o direcionamento ao Islã da mesma, como também a articulação de elementos liberais e iliberais. Convém destacar que a legislação contou com forte apoio de politicos tanto da esquerda quanto da direita, de intelectuais, unidos no entendimento de que o caráter secular da 
República Francesa estaria ameaçado por aspectos do Islã simbolizados pelo véu (ASAD, 2006).

$\mathrm{O}$ ex $1^{\circ}$ Ministro Jean-Pierre Rafflarin argumentou em 2004 que a lei que, indiretamente, baniu o véu, ajudará a garantir a "permanência dos nossos valores que constituem a nossa história coletiva e o principal fator da unidade moral ou espiritual de nossa nação" (O’BRIEN, 2016). De acordo com o então presidente francês Jacques Chirac, o véu, mesmo quando usado por estudantes, representa um "agressivo sinal de proselitismo religioso" (ibidem). As falas desses dois políticos indicam que, apesar de a lei estar ancorada na laicidade, ela também dispõe de elementos iliberais, que ressaltam valorações nacionais e intolerância religiosa.

Para Lochak (2004) a lei francesa sobre o uso de símbolos religiosos em escolas públicas é um agente duplamente iliberal em busca de um fim liberal: a norma não apenas obriga a pessoa a ser "autônoma", como também mobiliza o patriarcado para esse fim. Na mesma linha, Ordag (2010) aponta que os Estados europeus têm adotado politicas iliberais que violam os mesmos valores que eles buscam resguardar. Joppke (2014), ao refletir sobre a problemática da integração do Islã nas sociedades da Europa Ocidental, afirma que os esforços de normatização do corpo feminino têm empurrado o Estado liberal rumo a uma regulação legal da moral, colocando dessa forma em risco o próprio liberalismo. Esse parece ser justamente o caso desta lei francesa de 2004, com relação à qual argumentos liberais podem ser reunidos para justificar restrições no espaço público (ibidem).

A lei 2010-1192 de julho de 2010 também despertou acusações de islamofobia. Ela proíbe que o rosto dos indivíduos seja coberto por qualquer tipo de vestimenta em espaços públicos (LOI, 2010-1192). Com o argumento de que o véu completo islâmico questiona o caráter secular e de igualdade de gênero do modelo de integração francês, o governo francês promulgou a referida lei (THE GUARDIAN, 14.09.10). Similarmente ao caso anterior, embora a lei não especifique os muçulmanos ou a fé islâmica, a medida afetou de sobremaneira as mulheres muçulmanas que usam a burca ou o niqab, conforme indicam dados do próprio governo francês (RAPPORT ANNUEL DE L'OBSERVATOIRE DE LA LAÏCITÉ 2013-14, 2014). Além do 
conteúdo da medida legislativa, o qual estipula uma multa de 150 euros para quem desrespeitar a norma, chama a atenção a quase unanimidade que a lei obteve no parlamento francês: apenas um voto contrário no Congresso e no Senado (THE GUARDIAN, 14.09.10).

Joppke (2014), ao refletir sobre a lei francesa de 2010 e a respeito de sua análoga belga (2011), constata que essas legislações representam a mais drástica restrição imaginável em um Estado liberal contemporâneo. Assim, de forma similar ao caso alemão, o governo francês emprega medidas claramente iliberais para se chegar a fins liberais (JOPPKE, 2007a). Estas ações restritivas envolvem, potencialmente, a discriminação: a busca pela visão normativa do Estado liberal somente para pessoas liberais (ibidem). Nesse sentido, o ex-presidente Sarkozy é categórico:

Quem não deseja respeitar nossa concepção de humanidade, quem rejeita o humanismo, (...) quem deseja abolir a herança do Iluminismo e da Revolução [Francesa], quem não quer reconhecer que a mulher é igual ao homem, quem deseja aprisionar sua esposa em casa e forçá-la a usar o véu, quem deseja circuncisá-la ou submetê-la a casamento forçado, deve estar distante da França (LE MONDE 11-12, 2007 apud JOPPKE, 2007b, p. 271, tradução livre).

Trazendo para a discussão o conceito de liberalismo perfeccionista é possivel identificar algumas de suas premissas no caso da referida lei francesa. De acordo com O’Brien, “o liberalismo perfeccionista defende atos compulsórios em nome da emancipação daqueles que são incapazes de se libertarem por si mesmos" (2016, p. 112, tradução livre). Essa postura é muito bem ilustrada na fala do então Ministro da Imigração da França, Eric Besson (2009), que defendeu o banimento da burca com o argumento de que a "autoridade pública é fundada por meio da proteção da dignidade do indivíduo, se necessário indo contra a vontade da pessoa em questão" (JOPPKE e TORPEY, 2013).

Outrossim, perceber-se nesta lei francesa dois aspectos da islamofobia liberal conforme preconizado por Mondon e Winter (2017): o uso de argumentos liberais como a igualdade de gênero e o secularismo como justificativa para ações discriminatórias aos muçulmanos. Esses argumentos 
liberais se combinam com práticas iliberais que são responsáveis pela violação de direitos individuais, como a liberdade de expressão e a liberdade religiosa. Essa circunstância também é evidenciada por King (1999), que defende que algumas politicas na democracia liberal assumem características iliberais na medida em que violam dois princípios centrais do liberalismo: igualdade de tratamento e respeito pelas liberdades individuais.

Mais recentemente, a instauração do estado de emergência na França, logo após atentados terroristas de 13 de novembro de 2015, constituiu outra medida de restrição as liberdades da comunidade muçulmana francesa. O decreto foi estendido cinco vezes, até ser internalizado na legislação francesa, em outubro de 2017, sob a forma da nova lei antiterrorismo (FOLHA DE SÃO PAULO, 31.10.17). O estado de emergência permitiu a prisão de indivíduos suspeitos para a ordem e a segurança pública, o fechamento de locais de encontro de pessoas e a revista sem mandado judicial em domicílios durante o dia e a noite (GAUCHA ZH, 16.11.15). Organizações como a Human Rights Watch (2016) e a Amnesty International (2017) vêm denunciando que o estado de emergência tem sido utilizado para atacar muçulmanos, por meio de incursões abusivas, discriminatórias e também de prisões.

Essa situação também é evidenciada pela Freedom House (2015), quando afirma que em razão dos mortais atentados terroristas dos anos recentes, o governo francês restringiu proteções constitucionais e "empoderou" a aplicação da lei, afetando as liberdades individuais. No seu relatório de 2017 (p. 1, tradução livre) a Freedom House enfatiza que nesse contexto de crise gerado pelos recentes ataques terroristas, "Paris tem estado cada vez mais disposta a reduzir as proteções constitucionais e capacitar as forças policiais a agir de forma a prejudicar as liberdades pessoais".

A restrição das liberdades fundamentais se refletirá na qualidade da democracia francesa, conforme evidencia o The Economist Democracy Index 2015. A publicação sustenta que o aumento das restrições à liberdade dos cidadãos, em virtude do estado de emergência francês, gerou um aumento da deterioração da coesão social, impulsionando queda do país da categoria 
de full democracy para flawed democracy em 2015. Essa posição foi mantida por Paris na publicação do último relatório da The Economist em 2018.

Dentre os vinte e um países da Europa Ocidental, a França aparece na $17^{\mathrm{a}}$ colocação do The Economist Democracy Index (2017). A publicação destaca que "a incorporação dos poderes do estado de emergência dentro da legislação ordinária francesa [no final de 2017] representa uma ameaça potencial aos direitos e liberdades de vários grupos na França, e não somente a potenciais grupos e individuos terroristas" (THE ECONOMIST DEMOCRACY INDEX, 2017, p. 23, tradução livre). Hansen e King (2000) complementam destacando que, em momentos de crise politica, os valores básicos liberais das democracias ocidentais europeias competem com pressões iliberais (impulsos xenófobos, racistas e antissemitas).

Situado no contexto do estado de emergência e na esteira de outros atentados terroristas (como o atropelamento em Nice que matou 84 pessoas e feriu mais de 300), outra lei referente à vestimenta islâmica feminina foi acusada de ser islamofóbica. No dia seguinte ao atentado em Nice (15 de julho de 2016), o prefeito desta cidade decidiu banir o burkini (traje de banho usado pelas mulheres muçulmanas que cobre todo o corpo) em nome da manutenção da ordem e dos valores seculares franceses (THE GUARDIAN, 19.08.16). Na sequência dessa decisão, prefeitos de outras 28 cidades do país adotaram a mesma medida (LOUATI, 2017). Após essas novas determinações, diversos ataques contra mulheres que usavam o burkini ou mesmo véu foram registrados. Em alguns casos, policiais obrigaram essas mulheres a retirar a vestimenta ou retirar-se da praia (ibidem).

Essas proibições a respeito do burkini contaram com forte apoio do governo federal. O então premier Manuel Valls declarou, em agosto de 2016, que a vestimenta "não era compativel com os valores da França e da República”. Disse, ainda, que o burkini não representa um novo tipo de roupa de banho ou uma moda. É uma expressão de um projeto político, uma contra-sociedade baseada principalmente na escravização da mulher" (KROET, 2016, online). A declaração de Valls encaixa-se perfeitamente no ideal da islamofobia liberal: ela "proporciona à "Nós" um senso de justiça 
como defensores de uma visão mais progressista do mundo, deslocando para o Islã, as tensões e falhas originárias de uma visão atrasada (MONDON e WINTER, 2017, p. 14, tradução livre).

O caráter islamofóbico dessa lei pode igualmente ser observado na justificativa expressa pela Corte Administrativa de Nice, em 22 de agosto de 2016, para a validação da medida:

(...) A coexistência de religiões, a qual é elemento constitutivo do principio de secularismo, é oposta ao fundamentalismo religioso islâmico, que advoga por uma prática radical da religião, incompativel com os valores essenciais da comunidade francesa, bem como com o princípio de igualdade de gênero. Neste contexto, o uso de vestimentas na praia de modo a mostrar uma convicção religiosa de forma ostensiva pode ser interpretado como pertencente a esse fundamentalismo (NICE ADMINISTRATIVE TRIBUNAL apud LOUATI, 2017, p. 200-201, tradução livre).

No texto acima podemos observar uma interessante articulação discursiva entre ideais liberais e iliberais. Os primeiros são nítidos e expostos abertamente. Já os segundos estão subentendidos na compreensão etnocêntrica de que o uso de um adorno religioso (prática cultural distinta da maioria da população) representa a expressão de valores diferentes e inferiores. Ainda é possivel perceber uma tentativa da corte em estabelecer uma conexão entre o uso do burkini e a simpatia a grupos terroristas. A articulação desses distintos pressupostos culmina na imposição de uma normativa que resultará na restrição de direitos individuais.

Para Joppke (2017), ações iliberais tomadas a partir de pressupostos liberais têm se expandido sob o contexto do terrorismo islamista, particularmente na França, como se pode observar nas leis contra o burkini. Igualmente, estas legislações ressaltam novamente importantes articulações do liberalismo e do iliberalismo em prol de políticas islamofóbicas. A defesa do secularismo pelo Estado liberal acaba por gerar práticas iliberais como a restrição das liberdades individuais. Para King (1999), historicamente a defesa e a expansão de fins democráticos liberais parecem necessitar ocasionalmente de meios iliberais. Não obstante, pouco tempo depois das promulgações das proibições ao burkini, em 26 de agosto a Suprema Corte Francesa suspendeu o banimento da vestimenta (CNN, 26.08.16). 
Contudo, a constante adoção de medidas iliberais pelo Estado francês levou a Freedom House (2017) a reduzir, pela primeira vez em quatorze anos, o índice de "liberdades civis" na França. A instituição justificou a posição "devido a infrações de autonomia pessoal, em particular controles de vestimenta e símbolos religiosos, que se concentram, desproporcionalmente, sobre as mulheres situadas no contexto de ataques terroristas e medidas agressivas de contraterrorismo" (FREEDOM HOUSE, 2017, p. 1, tradução livre).

\section{Conclusão}

O presente artigo investigou as manifestações da islamofobia nas principais políticas públicas da Alemanha e da França. Observou-se que, embora ancoradas em fundamentos díspares (neutralidade estatal no primeiro caso e laicidade no segundo), ambas políticas públicas possuem um caráter islamofóbico diante os muçulmanos residentes em seus países. Igualmente, notou-se que a ação estatal por meio de leis encontra respaldo do mainstream politico de Berlim e Paris.

Através dos pressupostos do conceito do liberalismo perfeccionista, verificou-se o esforço dos Estados alemão e francês em disciplinar os seus cidadãos segundo o seu entendimento dos valores nacionais. Porém, esse empreendimento se mostrou discriminatório, na medida que a defesa de valores politicos (liberalismo) e culturais (Cristianismo na Alemanha e laicidade na França) legitimou a violação de liberdades fundamentais, como a de expressão e a religiosa.

Os conceitos de islamofobia liberal e islamofobia iliberal foram úteis ao lançarem luz sobre o grande paradoxo verificado pela ação estatal na Alemanha e na França: a defesa de valores liberais como o secularismo e a igualdade de gênero gerou práticas iliberais que atacaram direitos fundamentais dos indivíduos em razão de suas preferências religiosas. Nesse sentido, a investigação da islamofobia nas politicas públicas na Alemanha e na França permitiu inferir não apenas notáveis tensões entre o liberalismo e 
o iliberalismo, bem como a articulação entre ambos tem permitido a institucionalização de práticas islamofóbicas por Berlim e Paris.

Contudo, o impacto da islamofobia na qualidade democrática dos dois países mostrou-se diferente. A democracia francesa tem sofrido revezes importantes, ao contrário da alemã, conforme demonstrado nos últimos relatórios da Freedom House e da The Economist Democracy Index. A execução e incorporação de medidas iliberais de caráter mais amplo, como o estado de emergência/lei antiterrorismo, são responsáveis por expandir a restrição de direitos e das liberdades da comunidade muçulmana francesa, mostrando que a islamofobia está mais desenvolvida na França do que na Alemanha.

Por fim, destaca-se que o estudo do impacto da islamofobia sobre a qualidade da democracia de Berlim e Paris é uma agenda de pesquisa que ainda merecerá atenção em outros trabalhos científicos.

\section{Referências}

ALLEN, Christopher. The 'First' Decade of Islamophobia: 10 years of the Runnymede Trust report Islamophobia: a Challenge for us all. Stourbridge: Christopher Allen, 2007.

AMNESTY INTERNATIONAL. France's permanent state of emergency. 2017. Disponivel em: <https://www.amnesty.org/en/latest/news/2017/09/a-permanent-state-ofemergency-in-france/>. Acesso em 03 de outubro de 2017.

ARANI, Aliyeh. The network against discrimination and islamophobia - AntiMuslim racism and Islamophobia in Germany. Presented by The Network Against Discrimination and Islamophobia, March 2015. Disponivel em: < http://tbinternet.ohchr.org/Treaties/CERD/Shared\%20Documents/DEU/I NT_CERD_NGO_DEU_20112_E.pdf>. Acesso em 01 de julho de 2017.

ASAD, Talal. Formation of the Secular: Christianity, Islam, Modernity. California: Stanford University Press, 2006. 
BBC. Apresenta informações sobre os diferentes tipos de véu islâmico. Disponivel em:

http://news.bbc.co.uk/2/shared/spl/hi/pop_ups/05/europe_muslim_veils /html/1.stm>. Acesso em 03 de outubro de 2016.

BLEICH, Erik. Defining and Researching Islamophobia. Review of Middle East Studies, Vol. 46, No. 2, pp. 180-189, Winter 2012.

BOBBIO, Norberto. Liberalismo e Democracia. São Paulo: Editora Brasiliense, 2000.

BRINT, Steve. Gemeinschaft Revisited: A Critique and Reconstruction of the Community Concept. Sociological Theory, vol. 19, $\mathrm{n}^{\circ} 1$, pp. 1-23, mar. 2001.

CESARI, Jocelyne. Islamophobia in the West. In: ESPOSITO, J.; KALIN, I (Orgs.). Islamophobia: The Challenge of Pluralism in the 21st Century. Oxford: Oxford University Press, 2011.

CNN. French court suspends burkini ban. 26 de agosto de 2016. Disponível em: $\quad$ http://edition.cnn.com/2016/08/26/europe/france-burkini-bancourt-ruling/index.html >. Acesso em 5 de junho de 2017.

ECONOMIST DEMOCRACY INDEX 2015, The. A report by The Economist Intelligence Unit. 2015. Disponivel em: <https://www.yabiladi.com/img/content/EIU-Democracy-Index-2015.pdf>. Acesso em 04 de outubro de 2017.

2017, The. A report by The Economist Intelligence Unit. $2017 . \quad$ Disponivel em: http://www.eiu.com/Handlers/WhitepaperHandler.ashx?fi=Democracy_Inde $\underline{x \_2017 . p d f \& m o d e=w p \& c a m p a i g n i d=D e m o c r a c y I n d e x 2017}>$. Acesso em 04 de outubro de 2017.

EKELI, Kristian. Liberalism and Permissible Supression of Illiberal Ideias. Inquiry: An Interdisciplinary Journal of Philosophy, vol. 55, $\mathrm{n}^{\circ}$ 2, pp. 171193, 2012. 
EUROPOL. European Union Terrorism Situation and Trend Report 2016. Disponivel em: < https://www.europol.europa.eu/activities-services/mainreports / european-union-terrorism-situation-and-trend-report-te-sat-2016>. Acesso em 10 de agosto de 2017.

European Union Terrorism Situation and Trend Report 2015. Disponivel em: <https://www.europol.europa.eu/activities-services/mainreports/european-union-terrorism-situation-and-trend-report-2015>. Acesso em 10 agosto de 2017.

European Union Terrorism Situation and Trend Report 2014. Disponivel em: <https://www.europol.europa.eu/activities-services/mainreports/te-sat-2014-eu-terrorism-situation-and-trend-report>. Acesso em 10 de agosto de 2017.

EUROSTAT. Apresenta informações estatísticas sobre a União Europeia. Disponivel em: <http://ec.europa.eu/eurostat>. Acesso em 01 de julho de 2016.

FINKELKRAUT, Alain. Entrevista à Élisabeth Levy e Christophe Ono-DitBiot. Le Point Politica, 2013. Disponivel em: < http:/ / www.lepoint.fr/politique/alain-finkielkraut-etre-francais-ce-n-estpas-etre-une-composante-de-la-diversite-10-10-2013-1744071_20.php\#>. Acesso em 25 de outubro de 2017.

FOLHA DE SÃO PAULO. Macron sanciona lei antiterrorismo, que substitui emergência na França. 31 de outubro de 2017. Disponivel em: < http: / / www1.folha.uol.com.br/mundo/2017/10/1931704-macronsanciona-lei-antiterrorismo-que-substitui-emergencia-na-franca.shtml>. Acesso em 14 de novembro de 2017.

FREEDOM HOUSE. Freedom in the World 2015: France Profile. 2015. Disponivel em: <https://freedomhouse.org/report/freedomworld/2015/france>. Acesso em 05 de outubro de 2017.

Freedom in the World 2017: France Profile. 2017. Disponivel em: <https://freedomhouse.org/report/freedomworld/2017/france>. Acesso em 05 de outubro de 2017.

GARNER, Steve; SELOD, Saher. The racialization of Muslims - Empircal Studies of Islamofobia. Critical Sociology, vol. 41, $\mathrm{n}^{\circ}$ 1, pp. 1-11, 2014. 
GAUCHA ZH. Entenda o que é o estado de emergência decretado pelo governo francês. 16 de novembro de 2015. Disponível em: <https://gauchazh.clicrbs.com.br/geral/noticia/2015/11/entenda-o-que-eo-estado-de-emergencia-decretado-pelo-governo-frances-4904472.html>.

Acesso em 5 agosto de 2017.

GEISSER, Vincent. Islamophobia: a French Specificity in Europe? Human Architecture: Journal of the Sociology of Self Knowledge, Vol. 8, $\mathrm{n}^{\circ} 2$ Islam: From Phobia to Understanding, 2010.

GERMAN 2016 INTERNATIONAL RELIGIOUS FREEDOM REPORT. U.S. Department of State. Disponivel em: < https://www.state.gov/documents/organization/269062.pdf>. Acesso em 11 de agosto de 2017.

GUARDIAN, The. German elections 2017: full results. 24 de setembro de 2017. Disponivel em: <https://www.theguardian.com/world/nginteractive/2017/sep/24/german-elections-2017-latest-results-live-merkelbundestag-afd>. Acesso em 30 de setembro de 2017.

$\begin{array}{llll} & & \text { Nice becomes latest French city to impose burkini ban. } 19 \\ \text { de agosto } & \text { de } & 2016 . & \text { Disponivel }\end{array}$ $<$ https://www.theguardian.com/world/2016/aug/19/nice-becomes-latestfrench-city-to-impose-burkini-ban>. Acesso em 29 de agosto de 2017.

. France: Senate votes for Muslim face veil ban. 14 de setembro de 2010. Disponivel em: <https://www.theguardian.com/world/2010/sep/14/france-senatemuslim-veil-ban>. Acesso em 06 de maio de 2017.

HANSEN, Randall; KING, Desmond. Illiberalism and the New Politics of Asylum: Liberalism's Dark Side. The Political Quartely, vol. 71, $\mathrm{n}^{\circ}$ 4, pp. 396-403, October 2000.

HOLMES, Stephen. The Anatomy of Antiliberalism. Cambridge: Harvard University Press, 1993. 
HUMAN RIGHTS WATCH. France: Abuses Under State of Emergency. 2016. Disponivel em: < https://www.hrw.org/news/2016/02/03/france-abusesunder-state-emergency>. Acesso em 06 de maio de 2017.

Discrimination in the name of Neutrality: Headscarf Bans for Teachers and Civil Servants in Germany. 2009. Disponivel em:

https://www.hrw.org/sites/default/files/reports/germany0209_webwcover. pdf>. Acesso em 01 de julho de 2017.

JONES, Nick; BRAUN, Kerstin. Secularism and State Neutrality: the Headscarf in French and German Public Schools. Australian Journal of Human Rights, 2017.

JOPPKE, Christian. Civic integration in Western Europe: Three debates. West European Politics, 2017.

Islam and the Legal Enforcement of Morality. Theory and Society, vol. 43, nº 6, pp. 589-615, 2014.

Beyond National Models: Civic Integration Policies for Immigrants in Western Europe. West European Politics, vol. 30, $\mathrm{n}^{\mathrm{o}} 1$, pp. 1-22, 2007a.

Transformation of Immigrant Integration: Civic Integration and Antidiscrimination in the Netherlands, France, and Germany, World Politics, vol. 59, n 2, pp. 243-73, $2007 \mathrm{~b}$.

State Neutrality and Islamic Headscarf Laws in France and Germany. Theory and Society, vol. 36, n⿳ 4, pp. 313-342, 2007c.

JOPPKE, Christian; TORPEY, John. Legal Integration of Islam: A Transatlantic Comparison. Cambridge: Harvard University Press, 2013.

KAYA, Ayhan. 'Islamophobism' as an Ideology in the West: Scapegoating Migrants of Muslim Origin. In: AMELINA, Anna.; HORVATH, Kenneth.; MEEUS, Bruno (Orgs.). An Anthology of Migration and Social Transformation: European Perspectives. London: Springer, 2016. 
KEPEL, Giles. Entrevista à Ruth Grosrichard. La Dépêche, 2017. Disponivel em: < https://ladepeche.ma/toute-critique-de-lislam-interdite/>. Acesso em 25 de outubro de 2017.

KEPEL, Giles; ROUGIER, Bernard. Radicalisations et islamophobie: le roi est nu. Liberation. Disponivel em: < http://www.liberation.fr/debats/2016/03/14/radicalisations-etislamophobie-le-roi-est-nu_1439535>. Acesso em 25 de outubro de 2017.

KING, Desmond. In the Name of Liberalism: Illiberal Societal Policy in the United States and Britain. Oxford University Press, Oxford, 1999.

KROET, Cyinthia. Manuel Valls: Burkini 'not compatible' with French values. Politico. 17 de agosto de 2016. Disponivel em: <http://www.politico.eu/article/manuel-valls-burkini-not-compatible-withfrench-values/>. Acesso em 11 de agosto de 2017.

KYMLICKA, Will. Multiculturalism: Sucess, Failure and the Future. Migration Policy Institute, 2012.

Multicultural Citizenship: a liberal theory of minority rights.

Oxford: Claredon Press, 1995.

LETTINGA, Doutje; SAHARSO, Sawitri. Outsiders Within: Framing and Regulation of Headscarves in France, Germany and The Netherlands. Social Inclusion, v. 2, nº 3, pp. 29-39, 2014.

LOCHAK, Daniele. L'intégration, alibi, de la précarisation. Plein Droit, vol. 59-60, no 4. 2004.

LOCKE, John. Segundo Tratado sobre o Governo Civil e Outros Escritos. Petrópolis: Editora Vozes, 2001.

LOI 2010-1192. 11 de outubro de 2010. Disponível em: <https://www.legifrance.gouv.fr/affichTexte.do?cidTexte=JORFTEXT000022

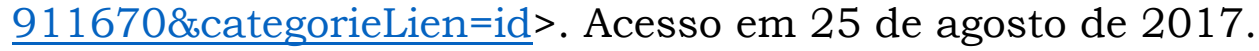


LOI 2004-228. 15 de março de 2004. Disponivel em: < https://www.legifrance.gouv.fr/affichTexte.do?cidTexte=JORFTEXT0000004

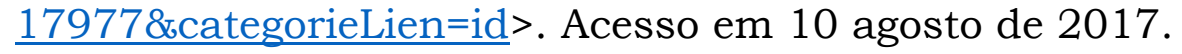

LORASDAGI, Berrin; INCE, Hilal. An Analysis of the Headscarf Issue in Feminist Debates in Germany. Uluslararast Iliskiler, vol.6, $\mathrm{n}^{\circ}$ 24, pp. 8198, winter 2010.

LOUATI, Yasser. Islamophobia in France: National Report. In: BAYRAKLI, E.; HAFEZ, F. (Orgs.). European Islamophobia Report 2016. SETA - Foundation for Political, Economic and Social Research, 2017.

MATTEUCCI, Nicola. Liberalismo. In: BOBBIO, Norberto.; MATTEUCCI, Nicola.; PASQUINO, Gianfranco (Orgs.). Dicionário de Política. Brasília: Editora UnB, 1998.

MERQUIOR, J. 2014. O Liberalismo: Antigo e Moderno. São Paulo: É Realizações.

MILL, John Stuart. Sobre a Liberdade. Petrópolis: Vozes, 1991.

MINISTĖRE DE L'ÉDUCATION NATIONALE DE L'ENSEIGNEMENT SUPÉRIEUR ET DE LA RECHERCHE. Application de la loi du 15 Mars 2004. Rapport à monsieur le ministre de l'éducation nationale de l'enseignement supérieur et de la recherché. Rapporteur Hanifa Chérifi, Paris, 2005. Disponivel em: < http://media.education.gouv.fr/file/98/4/5984.pdf $>$. Acesso em 11 de novembro de 2017.

MONDON, Aurelien; WINTER, Aaron. Articulations of Islamophobia: From the Extreme to the Mainstream? Ethnic and Racial Studies, vol. 40, $\mathrm{n}^{\circ} 13$, pp. 2151-2179, 2017.

O'BRIEN, Peter. The Muslim Question in Europe: Political Controversies and Public Philosophies. Temple University Press, 2016.

ORGAD, Liav. The Cultural Defense of Nations: A Liberal Theory of Majority Rights. Oxford: Oxford University Press, 2015. 
Illiberal Liberalism Cultural Restrictions on Migration. The American Journal of Comparative Law, vol. 58, $\mathrm{n}^{\circ}$ 1, pp. 53-105, 2010.

PEW RESEARCH CENTER. 2017. 5 Facts about the Muslim population in Europe. Disponivel em: <http://www.pewresearch.org/facttank/2017/11/29/5-facts-about-the-muslim-population-in-europe/>.

Acesso em: 10 de dezembro de 2017.

RAPPORT ANNUEL DE L'OBSERVATOIRE DE LA LAÏCITÉ 2013-14. 2014. Observatoire de la laïcité, Paris. Disponivel em: <http: / / www.gouvernement.fr/ rapport-annuel-de-1-observatoire-de-lalaicite-2013-2014>. Acesso em 11 de novembro de 2017.

RILEY, Angela. (Tribal) Sovereignty and Illiberalism. California Law Review, vol. 95, nº 3, pp. 799-848, 2007.

ROSANVALLON, P. 2001, Fondements et problèmes de 1' illibéralisme français. Disponivel em: < https://www.asmp.fr/travaux/communications/2001/rosanvallon.htm>.

Acesso em 05 de março de 2018.

RUA, Maria das Graças. Análise de politicas públicas: conceitos básicos. Textos elaborados para o Curso de Formação para a carreira de Especialista em Politicas Públicas Gestão Governamental. Brasília: ENAP/ Ministério do Planejamento, 1997.

RUNNYMEDE TRUST, The. Islamophobia: a Challenge for Us All. Report of the Runnymede Trust Commission on British Muslims and Islamophobia. London: The Runnymede Trust, 1997.

SOUZA, Celina. Políticas Públicas: uma revisão da literatura. Sociologias. Porto Alegre, ano 8, n 16, pp. 20-45, jul/dez 2006.

SPIEGEL. From Black to Orange: Spiegel Online's Guide to German Political Parties. 28 de fevereiro de 2013. Disponivel em: <http://www.spiegel.de/international/germany/guide-to-german-politicalparties-a-886188.html>. Acesso em 07 de setembro de 2017. 
ULGER, Irfan.; BENITEZ, Maribel. Islamophobia in France, from racism to “neo-populism”. LAÜ Sosyal Bilimler Dergisi, (VIII-I), pp. 50-66, 2017.

WEBER, Barbara. Hijab Martyrdom, Headscarf Debates: Rethinking Violence, Secularism and Islam in Germany. Comparative Studies of South Asia, Africa and The Middle East, vol. 32, nº 1, pp. 102-115, 2012.

- Cloth on Her Head, Constitution in Hand: Germany's Headscarf Debates and the Cultural Politics of Difference. German Politics and Society, 22, $n^{\circ} .3, p p .33-63,2004$.

YOUNES, A. Islamophobia in Germany: National Report. In: Bayrakli, E.; Hafez, F. (Org). 2018. 